REVISTA CHILENA DE LITERATURA

Noviembre 2020, Número 102, 355-379

\title{
LA ESCRITURA TRANSVERSAL DE RAFAEL ARGULLOL
}

\author{
Paulo Antonio Gatica Cote \\ Universidad de Santiago de Compostela \\ Santiago de Compostela, España \\ paulo.gaticacote@gmail.com
}

\begin{abstract}
RESUMEN / ABSTRACT
En este artículo examino la denominada escritura transversal, el proyecto intelectual y literario de Rafael Argullol y uno de los ejes vertebradores de su obra. Para el ensayista barcelonés, la transversalidad resulta una especie de epifanía expresiva en la que se conjugan el fragmento o el aforismo. Así, el autor pretende transparentar la emergencia y el flujo natural del pensamiento, en cuanto experiencia sensible e intelectiva, por medio de una serie de fugas y disonancias transgenéricas que refuerzan su concepción nómada y plural de la creación y de la existencia.

PALABRAS ClAVE: Rafael Argullol, escritura transversal, aforismo, nomadismo, estética de lo efímero.

THE TRANSVERSE WRITING OF RAFAEL ARGULLOL

In this paper I examine the so-called transverse writing, the intellectual and literary project of Rafael Argullol and one of his work's core. To the catalan essayist, the transverse writing involves an expressive epiphany in which the fragment and the aphorism are conjugated. Thus, the author tries to make transparent the emergence and the natural flow of thought, as sensitive and intellective experience, through a series of transgeneric fugues and dissonances that reinforce his nomadic and plural conception of creation and existence.
\end{abstract}

KEYWORDS: Rafael Argullol, transverse writing, aphorism, nomadism, aesthetic of the ephemeral.

Recepción: 12/05/2018

Aprobación: 28/06/2018 
El mundo tiene fronteras: las que tú te pongas.

Rafael Argullol

Pocos autores se han situado con tanta facilidad en la encrucijada de los géneros literarios como Rafael Argullol (1949). Su escritura caleidoscópica se ha sabido acomodar con éxito a los cauces narrativos, ensayísticos y líricos y, al mismo tiempo, mantener un cierto "espíritu" común a todas y cada una de sus realizaciones ${ }^{1}$. Además, el barcelonés se muestra particularmente hábil en el cultivo de la autodenominada escritura transversal en libros inclasificables como El cazador de instantes. Cuaderno de travesía 1990-1995 (1996), El puente de fuego. Cuaderno de travesía 1996-2002 (2004), Enciclopedia del crepúsculo (2005), Breviario de la aurora (2006) y, en menor medida, Tratado erótico-teológico. Un relato (2016). Para Argullol, la "transversalidad" se movería entre los polos modernos de la fragmentación y de la obra de arte total, entre las poéticas del silencio y la utopía expresiva totalizante ("Escritura transversal" 34); sin embargo, esta escritura no opera de un modo dialéctico, sino que se manifiesta justamente en sus "disonancias" y fugas genéricas.

El propio Argullol considera su escritura "menos reposada que la poética, menos argumental que la narrativa, menos analítica que la filosófica, (...) atraviesa distintos ámbitos de expresión sin detenerse en uno exclusivamente" (El puente de fuego 14). El funambulismo estilístico del barcelonés no se deja

1 Según la web personal de Rafael Argullol, las siguientes obras se adscribirían al género narrativo: El enigma de Lea (2019), Poema (2017), Mi Gaudi espectral. Una narración (2015), Pasión del dios que quiso ser hombre (2014), Davalú o el dolor (2001), Transeuropa (1998), La razón del mal (1994), Desciende, río invisible (1989), El asalto del cielo (1986), Lampedusa (1981); dentro del género ensayístico incluiría Maldita perfección. Escritos sobre el sacrificio y la celebración de la belleza (2013), Manifiesto contra la servidumbre. Escritos frente a la guerra (2003), Una educación sensorial. Historia personal del desnudo femenino en la pintura (2002), Aventura. Una filosofía nómada (2000), Sabiduría de la ilusión (1994), El fin del mundo como obra de arte (1990), Territorio del nómada (1986), Tres miradas sobre el arte (1985), Leopardi. Infelicidad y titanismo (1985), El Héroe y el Único (1984), La atracción del abismo (1983), El Quattrocento (1982); con respecto al género lírico menciona Poema (2017), "Warcant" (2014), “Alegato contra la codicia" (2012), Cantos del Naumon (2010), Poema de la serpiente (2010), El afilador de cuchillos (2010), Duelo en el Valle de la Muerte (1986), Disturbios del conocimiento (1980). Además, menciona los diálogos-Moisès Broggi, cirugià, l'any 104 de la seva vida (2013), Del Ganges al Mediterráneo (2004), El cansancio de Occidente (1993). Finalmente, el libro Visión desde el fondo del mar (2010) cuenta con un apartado propio. 
seducir por "el instinto de unidad" (Schlegel 47), por la imagen de un sistema, bella y perfectamente cerrado como el erizo de Schlegel (105); en cambio, el autor encuentra en estas formas una suerte de metaestructura "abierta, sutil e invisible" (Argullol, Aventura 10) que le permite reflexionar sobre el propio proceso del pensamiento en su devenir forma o, mejor dicho, devenir presencia. En este sentido, su escritura tiene mucho de sístole y diástole de la inteligencia, de respiración mental que pone en marcha un aparato conceptual flexible, posicionado en una triple coordenada del saber-vivir y sentir-(Argullol, Aventura 35): un conocimiento sobre nosotros mismos, un conocimiento sobre nuestros semejantes y un conocimiento sobre el mundo.

\section{EL LÓGOS DEL NÓMADA}

Desde una visión científica de corte positivista y autolegitimadora, el conocimiento se obtiene, grosso modo, tras la aplicación de una metodología que busca "descomplejizar" y describir la realidad por medio de principios universales y verificables. Existiría una confianza prácticamente ciega en las capacidades intelectuales del ser humano y, por tanto, en su capacidad para articular un metalenguaje universal que permita la transmisión de dichos principios: si todo se puede descubrir-comprender-explicar, todo ha de ser, en consecuencia, comunicable. Según Argullol, el discurso científico se ha dejado llevar por la hybris de una sociedad tan tecnologizada como monolítica. Por ello, ante este modelo de conocimiento supuestamente progresivo, el filósofo barcelonés plantea la recuperación de una "sabiduría de la duda": "la fuerza que puede proporcionar una conciencia de la ciencia al recordar, de continuo, quién es el destinatario de todo saber" ("El velo de Isis")2.

Precisamente, Rafael Argullol propone en su lucha contra las lógicas binarias darle la vuelta al razonamiento para generar zonas en las que el "recto sentido" se ve "oscurecido" por su insuficiencia. Así, en Aventura habla de la necesidad de una "filosofía dancística" que supere las limitaciones del andamiaje casi silogístico sobre el que se ha erigido el conocimiento occidental.

2 En concreto, Argullol retoma la metáfora del "velo de Isis" que, en el romanticismo alemán, remitía al umbral que delimitaba la entrada a los "conocimientos últimos". Para el autor, se podría establecer una dicotomía entre aquellos que prefieren no traspasar el velo para protegerse de los incognoscibles y los que anhelan desvelar -y dominar- sus secretos (Enciclopedia 18). 
El ensayista comparte con Nietzsche la articulación poético-dionisíaca de una filosofía centrada en la "sabiduría de los sentidos" como la única vía de escape del edificio metafísico en el que parece atrapado el pensamiento: "El pensamiento siente los límites de todas las cosas mientras la sensación piensa que todas son ilimitadas. Recorridos todos los senderos del bosque siempre volvemos a la misma encrucijada" (Argullol, El cazador 56-57). Si se leen con atención las iluminaciones de Argullol se aprecia la confluencia de la mirada -la teoría- y la acción -la práctica-, de la experiencia y del experimento (Aventura 106). Para el filósofo resulta una obsesión romper con cualquier dicotomía asentada en modelos esencialistas o neocartesianos que avalan la supremacía de la mente.

En efecto, no se puede descomponer la escritura transversal, en cuanto experiencia sensible e intelectiva, en unidades discretas sin menoscabo. Tal como apunta Julio César Galán en un interesante trabajo, la escritura de Argullol se posiciona más allá del binomio "literatura pura" y "literatura de ideas" pues, en vez de arraigarse en alguno de los polos de ese manido debate forma/contenido - o cualquiera de sus variantes-, demuestra en todo momento su proteicidad (109). Igualmente, como aclara Oriol Alonso Cano, este "pluralismo metodológico" responde a un "pluralismo ontológico" de base; de ahí que considere errado el establecimiento de cualquier metodología reductora o indiferente a dicha pluralidad. En su opinión, la única aproximación "válida" para la captación de la experiencia "prerreflexiva" como "ámbito originario" del conocimiento solo puede venir de una "conceptualidad dinámica, fluyente e histórica" (303).

En relación con este sentido "impuro", su obra plantea una feroz crítica del racionalismo instrumental, construido en torno a lógicas binarias que falsean la complejidad del mundo y que, en palabras de Michel Maffesoli, "sofocan y excluyen fragmentos enteros de la vida" (Elogio de la razón 36). Para el sociólogo francés, la razón instrumental ha sido resensibilizada y reconvertida en una suerte de epistemología de las emociones (Elogio de la razón 68), un modo de conocimiento pertinente para el análisis de los fenómenos sociales contemporáneos. Por esta razón, el "saber sentir" argulloliano, feliz combinación de conocimiento y sentimiento, recompondría la "unidad perdida" durante el imperio del lógos metafísico 3 . Como reconoce

Al respecto, merece la pena mencionar que este impulso se materializó incluso en su diseño de la asignatura de Historia de la Filosofía en la Universidad de Barcelona: "Yo he 
el ensayista barcelonés, su producción conjuga el acto y la potencia de una razón sensible que, en términos de Maffesoli,

sustituye la representación por la presentación de las cosas, sin que ello significa negar la importancia de las representaciones en la construcción de la realidad y que esta representación se ocupe de reconocer lo que le sirve de soporte, que se identifique con el mundo que se supone aprehende y hasta explica. (Elogio de la razón 25)

Por su parte, la verdad argulloliana se presenta desteologizada; es decir, libre de cualidades "institucionales" o "privativas". El conocimiento no se custodia en ningún archivo ni se exhibe bajo la supervisión de sus transmisores. De acuerdo con Heidegger, la "esencia de la verdad" es el resultado de un proceso agónico de "conquista" de un centro abierto en el que el ente aparece replegado sobre sí mismo (77). Así, frente a la concepción "administrativa" de la verdad, que incide en la dialéctica búsqueda-aprendizaje, el autor reivindica, ante el hallazgo, la posición enigmática del poeta-viajero.

Bajo la etiqueta del nomadismo se ha producido una peligrosa generalización o equivalencia entre las nociones de aventura y de "autenticidad". En contraposición a esa sabiduría del viaje, entendido como singladura iniciática, se erige la figura del turista hipermoderno que vive, de acuerdo con Argullol, seducido por la apariencia de lo genuino. Mientras que el nómada aventurero se lanza a los caminos sin centro ni dirección aparente, el turista vive enfermo de amnesia, velocidad y cuantificación ("Provincianos y cosmopolitas"). Su obsesión es registrar y compartir lo vivido en forma de testimonio de pertenencia y participación en los usos y costumbres de una determina clase social. Ante este panorama, se comprende que la resistencia del viajero contemporáneo, inmerso en una permanente e inane movilidad, pueda consistir en un cierto elogio de la "quietud", en la negativa a participar en estas transacciones e intercambios prediseñados de vida:

mezclado siempre filósofos y literatos (...). Yo armé un cierto escándalo al hacer una historia de la filosofía donde estaba Sófocles y Shakespeare porque siempre he entendido que el mejor pensamiento transcurre a través de los escritores y de los artistas. Coincido con lo que dijo Nietzsche cuando afirmó que, a veces, en la cultura europea se había pecado de haber hecho una filosofía sin cuerpo, es decir, una filosofía que no pasaba por los sentidos y las emociones; una escisión demasiado profunda entre pensamiento y emociones, en definitiva, entre cuerpo y conciencia" (Argullol y Djermanovic, "La filosofía, arte del pensar" 110). 
(...) Siempre, no obstante, nos queda el recurso de ir a contracorriente y considerar que hoy la aventura es evitar cuidadosamente el viaje organizado total que se nos propone. A veces incluso es recomendable permanecer muy quietos, inmóviles, para empezar a viajar (La quietud). (Argullol, El puente de fuego 48)

Ahora bien, la cuidada planificación del viaje produce un paradójico efecto tranquilizador para la conciencia del turista: proporciona un sucedáneo de descubrimiento. Según el "vocabulario" de Argullol, me atrevería a decir que el turista asume las actitudes del "provinciano global" con vocación "cosmopolita". Aun cuando el contacto con la alteridad empuja inexorablemente al cosmpolita a "habitar la complejidad del mundo", el atractivo enigma de los bárbaros no logra el mismo efecto en el provinciano, pues este buscará primero un cierto equilibrio u homeostasis sujeto-entorno:

El cosmopolita, al no soportar la excesiva claustrofobia de la identidad propia, busca en el espacio absorto de lo ajeno aquello que pueda enriquecer su origen y sus raíces (...). El provinciano global quiere acumular mientras, simultáneamente, elimina o aplana las diferencias. (Argullol, "Provincianos y cosmopolitas")

Al respecto, Argullol va a retomar aquí una imagen muy difundida por la poesía contemporánea: el hallazgo - nada fortuito- de pecios. Sin embargo, cabe recordar la advertencia de uno de los mejores buscadores de tesoros marinos, Rafael Sánchez Ferlosio, en su pseudoprólogo metaliterario a Campo de retamas. Pecios reunidos:

Desconfíen siempre de un autor de "pecios". Aun sin quererlo, le es fácil estafar, porque los textos de una sola frase son los que más se prestan a ese fraude de la "profundidad", fetiche de los necios, siempre ávidos de asentir con reverencia a cualquier sentenciosa lapidariedad vacía de sentido pero habilidosamente elaborada con palabras de charol. Lo "profundo" lo inventa la necesidad de refugiarse en algo indiscutible, y nada hay tan indiscutible como el dicho enigmático, que se autoexime de tener que dar razón de sí. La indiscutibilidad es como un carisma que sacraliza la palabra, canjeando por la magia de la literalidad toda posible capacidad significante. (11)

El corpus de la literatura sapiencial, vertebrado por expresiones breves y condensadas, muestra, además de una función práctica-la transmisión de un conocimiento memorable-, una serie de presupuestos ideológicos acerca de 
la legitimidad y del "valor" allí inscritos. Por ello, el mero hecho de coincidir con los atributos "externos" de las paremias concede a sus émulos una pátina de respetabilidad formal y temática, que se traduce en esa "indiscutible" profundidad que denunciara Sánchez Ferlosio. Para el escritor español, esta aurificación de la palabra, ocasionada, en buena medida, por el mero marchamo de la brevedad, provoca la sacralización del significante. De este modo, el aforismo, el fragmento o la máxima adquieren un "poder performativo" que evitaría cualquier cuestionamiento de la literalidad explícita e implícita:

Todo el vigor de su función significante se desplazó a favor de su poder performativo en su valor de "símbolo de fe", o sea de credencial de integración y pertenencia, como lo muestra esa reunión de una exigencia de rigor en cuanto a literalidad y una total indiferencia en cuanto a comprensión: no hace falta entender, basta acatar. (Sánchez Ferlosio 12)

Rafael Argullol le da una vuelta de tuerca al Tractatus de Wittgenstein, puesto que, a diferencia del filósofo austríaco, el lenguaje no marca los límites del pensamiento, sino que el primero trabaja a la inversa: restringe el acceso a una verdad inexpresable mediante las herramientas lingüísticas disponibles. En el fondo, Argullol se interroga sobre la existencia de una verdad prelógica que, a la manera de Heidegger, anteceda a su formalización lingüística. De nuevo, el escritor se enfrenta a la denominada por José Ángel Valente como "primera paradoja del místico": "señalarnos desde el lenguaje y con el lenguaje una experiencia que el lenguaje no puede alojar" (317).

Así pues, el lenguaje nos empuja hacia la experiencia de sus límites, de su comunicabilidad y, por supuesto, de su imposibilidad ${ }^{4}$. El pensamiento de los confines ha atraído hacia sí buena parte de las poéticas que viven a un paso del hermetismo. Desde esta perspectiva, algunas de las corrientes literarias místicas o esencialistas han centrado sus inquisiciones en el desvelamiento del punto de partida lingüístico: el lógos ên arché o la singularidad sígnica que refiere a un instante cero de la significación. En cierto modo, esta búsqueda supone el religamiento in origine de un significante y de un significado

4 Con ánimo de superar dicha tensión, el símbolo se ha convertido en uno de los medios principales empleados para sobreponerse a las carencias del lenguaje (Bundgaard 434). 
no marcados ni pendientes de ser llevados a la presencia ${ }^{5}$. Además, según Heidegger, solo la poesía sería capaz de llevar Dichtung hacia la Lichtung; o sea, para el filósofo alemán solo lo poético -el "decir de la desocultación del ente" (97)- puede producir esa apertura "pacífica" por la cual se entrevé ese "misterio" arcano.

Por consiguiente, el lenguaje, más que morada del ser, se convierte en el "subterfugio" utilizado por la verdad para protegerse (Argullol, El cazador de instantes 63). No obstante, la completa "ilustración" conllevaría el fatal desvelamiento de esta necesaria cobertura para sobrellevar que "en esas honduras el aire escasea y la asfixia es inevitable", que la verdad y sus instrumentos carecen de vida (Argullol, El puente de fuego 136). Al igual que el lenguaje, la verdad no resulta unívoca ni recta, sino múltiple y sinuosa. De hecho, como explica Bundgaard sobre el pensamiento de María Zambrano, "la verdad nunca se revela del todo" (423), excepto brevemente y de manera "auroral" (El hombre y lo divino).

La idea de un "conocimiento fulgurante" o epifánico se aproxima a conceptos que beben de la tradición mística para expresar una particular relación entre la subjetividad y la objetividad. A través de un lenguaje que confía en la intuición y en la analogía, el poeta encuentra un camino que revierte los senderos trillados por la metafísica iluminadora, que, en buena medida, se sustentan en la correlación de la mirada del sujeto cognoscente con la "realidad". Por otro lado, esta experiencia liminal se va a traducir en los esfuerzos de la escritura -un sistema de signos- por plasmar unos "estados privilegiados de la conciencia" (Valente 306). En consecuencia, la materialización de esas pocas palabras sustanciales se concibe desde la resistencia efectiva a la inevitable inefabilidad del "misterio" revelado o por revelar.

En este sentido, la transversalidad posee en la escritura de Argullol el rango de "religión profana" (Steiner) en un sentido ontológico, marcadamente metalingüístico y anti-doctrinal. La insuficiencia de la palabra no denuncia la incapacidad "práctica" de la sintaxis o del léxico, sino que señala la distancia previa existente entre lo denotado y lo connotado más allá de su frontera

\footnotetext{
Para Fernando Infante, Argullol es un "pensador del origen", ya que su escritura se muestra "sensible a la indeterminación de lo primigenio y a su pérdida en el fracturado mundo de las identidades, nostálgicos del uno primordial pero habituados a gozar del devenir como reminiscencia reiterada de aquel origen" (160).
} 
semántica o referencial. En uno de sus muchos acercamientos al fenómeno poético desde la mística, José Ángel Valente afirma que "la cortedad del decir, la sobrecarga de sentido del significante es lo que hace, por virtud de éste, que quede en él alojado lo indecible o lo no explícitamente dicho" (88). Para el poeta español de la segunda promoción de posguerra, la palabra poética, entiéndase palabra esencial, se sustrae de cualquier temporalidad discursiva o contexto comunicativo; de este modo, el lenguaje conservaría su carácter intraducible y mostrativo. El aforismo supone un claro ejemplo de "sobrecarga de sentido del significante", pues, en su renuncia a cualquier desarrollo discursivo subyace un lógos nomádico que, además de fundar y transgredir continuamente su propia enunciación, articula un espacio textual/ referencial tanto autónomo como interdependiente.

\section{RAFAEL ARGULLOL, CAZADOR DE INSTANTES}

Conviene recordar junto a María Zambrano que el sacrificio ha sido una de las prácticas culturales empleadas para revelar la realidad. De acuerdo con la filósofa malagueña, este acto de patentización "fuerza" la comparecencia de lo divino; es decir, provoca una hendidura "instantánea” en el mundo y a través de la cual el mundo se exhibe plenamente (55). Sin embargo, el aprendizaje exige a los "iniciados" "la lentitud de la hormiga y la velocidad del águila" (Argullol, Breviario 14) en su singladura literaria-vivencial para usar las palabras con propiedad y consciencia de los significados allí guardados. En definitiva, se trata de aprender a usar el lenguaje con originalidad -relativo al comienzo, al origen- con independencia de su valor de cambio:

160. Dios, amor, verdad: antes de pronunciar cualquiera de esas palabras deberíamos subir al pico más alto o atravesar el desierto más árido. Nos basta, sin embargo, el regateo de mercado y, con tal de que el precio sea bajo, estamos dispuestos a dar por auténtica cualquier falsificación (Las grandes palabras). (Argullol, El puente de fuego 69)

De un modo análogo, el elocuente título de la primera cala "transversal" de Rafael Argullol, El cazador de instantes consagra el instante como núcleo significativo de una poética del tiempo y, por ende, de la memoria. Sirva de ejemplo la composición "La libélula" de El puente de fuego: 
335. Cuando pienso en lo mejor de la infancia recuerdo el leve aleteo de la libélula sobre el charco: el mundo era rojo y brillante como su cuerpo y el futuro olía como la tierra mojada tras las lluvias de septiembre. No sé si entonces comprendía la belleza de aquel rubí detenido en el aire. Pero sentía su poder: mantenía a raya los inviernos (La libélula). (127-128)

Al igual que, según Walter Benjamin, la imagen dialéctica es una "imagen en discontinuidad" (Libro de los pasajes 464), el instante argulloliano forma una constelación de tensiones temporales entre el pasado y el presente. Claramente, la lírica ha asumido de una forma más directa la búsqueda de ese "instante fecundo" en el que el tiempo detiene su fluir horizontal y se hace profundo, vertical ${ }^{6}$. Al respecto, la pluralidad temporal o de las experiencias subjetivas del "tiempo griego", evocada por la tríada chrónos -tiempo lineal-, aión -"tiempo de vida"- y kairós -momento oportuno-, puede servir de acercamiento a la cuestión. Para Christine Buci-Glucksmann, el instante, lo efímero consiste en la "conquista del momento favorable" (21) o kairós $^{7}$. Desde este punto de vista, la verticalidad anularía el desplazamiento horizontal de la metafísica, puesto que el instante revoca el devenir e impone "una dialéctica en estado detenido" (14), un ritmo fulgurante, epifánico. Si se extrapola dicha valoración de lo efímero a la praxis de Argullol, se observa que la escritura transversal recoge perfectamente en su expresión la idea de un tiempo no concebido como duración bergsoniana, sino como una especie de sucesión no sucesiva de instantes iluminadores.

Según la definición aforística de Argullol, el instante vendría a ser "un enigma que interrumpe el curso de las cosas demasiado conocidas" (Breviario 65). De esta manera, ese misterio o conocimiento omitido y por descubrir produce la interrupción de la linealidad, el ralentizamiento y el opacado del fluir semiótico. El enigma no ha de ser apreciado entonces como un agente

6 Como expresa Roberto Juarroz en el décimo poema de su Quinta poesía vertical: "Hay vidas que duran un instante: / su nacimiento. // Hay vidas que duran dos instantes: / su nacimiento y su muerte. // Hay vidas que duran tres instantes: / su nacimiento, su muerte y una flor". (168).

Buci-Glucksmann distingue dos formas de lo efímero, en cuanto arte del tiempo o kairología: lo efímero melancólico -"que revive y reactualiza sin fin el pasado y sus huellas"y lo efímero afirmativo-cósmico - "que integra, acepta y transforma la 'fluidez' de los flujos electrónicos desviando sus efectos y creando imágenes-flujo que pretenden ignorar la 'urgencia simulacro' del mercado" (22, 48-49). 
clarificador. Al contrario, la formulación de un saber no presente o llevado a la presencia por medio de su ausencia, promueve la revalorización de las zonas intermedias del signo lingüístico. En este sentido, parafraseando a Julio César Galán, el enigma se convierte en el "campo de pruebas" de la errancia que el "trotaideas" decide recorrer sin roturar (105).

De todas formas, cualquier medida de tiempo, incluso en su arbitraria linealidad cronológica, se compone de ritornellos, rituales y espacializaciones que generan redundancias y eternidades efímeras (Maffesoli El instante eterno ... 69). La reconciliación de las ideas de progresión e instante materializa en las páginas del libro un eterno retorno y recomienzo de esos momentos oportunos. Empero, cabe preguntarse si esta cacería de "momentos áureos" no conllevaría una especie de unificación, si "aparte de una labor evocadora, puede ser una elección, una disposición, una actitud ante la existencia" (Argullol, El cazador de instantes 15, 23-24).

En términos de Bachelard, la poesía compone una "metafísica instantánea" (93) que tiende puentes no dialécticos entre el sujeto y el objeto. Para el filósofo francés, el instante poético conforma una temporalidad vertical -ya sea por altura o por profundidad- que, a su vez, está constituida por un tejido de "simultaneidades" (94). Ahora bien, a diferencia de la simultaneidad esgrimida por Argullol en su colección de instantáneas, el "instante poético" supone una especie de "referencia autosincrónica" (Bundgaard 96) -o, incluso, autocontradicción- que emerge en tensión con la durée. La aparente anti-sucesividad de la lírica no significa la negación del tiempo lineal, sino la disposición ordenada y subjetiva de esos instantes "emergentes" que la realidad parece subsumir en una única narración o régimen temporal "histórico". De alguna manera, la objetividad del tiempo es revocada por la idea de una experiencia tan íntima como intensa.

En consecuencia, entre el pre y el post se sitúa el ahora argulloliano, aunque, en su caso, carga con el peso de lo "obvio" o de lo evidente, como categorías ya dadas o, lo que es más preocupante, como lo visible. Según el autor, la sociedad ha caído en las garras del "Gran Hechicero" que, a través de su arma más poderosa, la "Historia", se encarga de proporcionar "pasajeros antídotos del placer" (El puente de fuego 45) para compensar la absoluta sumisión a una de sus prerrogativas y exigencias temporales: evitar "la cesura en el movimiento del pensar", pues "al pensar pertenece tanto el movimiento como la detención de los pensamientos" (Benjamin Libro de los pasajes 478). Así, "la ilusión de continuidad" (Cappannini 45) anularía el "momentum dialéctico" negativo con el objeto de sumergir la percepción 
en una perenne reconciliación capitalista entre los momentos afirmativo y sintético. En palabras de Argullol:

Este otro tiempo, mediante el que reconocemos el relato secreto de nuestra existencia, no admite la imagen de un continuum sino que, al contrario, se manifiesta con violentas discontinuidades, (...) captamos su presencia en forma de instantes (...). En nuestro relato secreto cada uno de estos instantes encierra un mundo autosuficiente y, asimismo, en permanente transformación. (El cazador de instantes 14)

Sin duda, la poética del instante funge de dique para que la corriente del razonamiento lineal no someta artificialmente a esa razón sensible que se expresa de manera discontinua. Por esta razón, el montaje que realiza Argullol de los textos cazados provoca una conjunción más que la subordinación de los mismos a una estructura incardinadora. Como explica Cecilia Cappannini acerca del concepto de montaje en Benjamin,

el montaje provoca una hendidura, la percepción de una distancia entre las dos partes montadas que son 'interrumpidas' o sacadas del lugar en el que se encontraban (...). El montaje genera una constelación de sentido: se establecen conexiones significativas - no mediadas por ninguna explicación/interpretación teórica- a partir de un conjunto de elementos independientes y distantes. (47)

\section{LA ESCRITURA TRANSVERSAL}

Sin lugar a duda, la conjunción de experimento y experimentación atraviesa toda su obra. Rafael Argullol realza su filiación con Montaigne y con el ensayo como género que procede por medio de tentativas siempre parciales. La escritura transversal nunca camina sobre un plano formal prefijado, sino que explora y cartografía al mismo tiempo. Al arraigarse a la vida como fuente de intelección sensible, el autor elabora una topografía del conocimiento ligada al tránsito del sujeto explorador. De esta manera, la trayectoria fecunda una razón estéril asociada con la inmovilidad del yo. Es más, se desprende de su cosmovisión un elogio romántico de la juventud como fuerza motriz que, en este caso, más que exaltar la energía y el proyecto transformador de una educación sentimental, realza "nuestra capacidad de interrogar y nuestra capacidad de vivir": la predisposición vitalista a "ponerse en juego" 
(Argullol, Aventura 45). Como sentencia Argullol en uno de sus textos más breves: "Algunos, pocos, estamos en el ruedo; los demás, espectadores, juzgan desde las gradas. Así no corren el riesgo de morir, ni el de vivir" ( $E l$ puente de fuego 83).

En su ensayística, la subjetividad resulta constantemente interpelada por su retrato cinético, por múltiples puntos de vista que abandonan cualquier atisbo de predominio apenas el yo siente el vértigo reductor de la perspectiva. Como ilustra Rubio Martín acerca de Visión desde el fondo del mar-si bien puede referirse a otras composiciones transversales-, Rafael Argullol ejecuta la "deconstrucción de la autobiografía para componer el mito personal construido a partir de los instantes capturados por la memoria" $(87)^{8}$. El yo aparece doblemente enmascarado por su propio relato, ya que no solo ha de contar con el proceso enunciativo, sino que también debe ser esquivo a cualquier codificación que desambigüe la "sopa de sensaciones" que lo origina y alienta.

En suma, Argullol expresará constantemente este anhelo de voyeur que contempla y se contempla en lo contemplado desde una pluralidad de miradores: "Me gustaría, de vez en cuando, contemplar la existencia desde el otro lado. Hacerlo siempre desde mi lado es agotador, además de parcial. Me gustaría mirarme desde fuera, pensar sobre mí con una mente ajena" ( $E l$ cazador de instantes 32). A su entender, el escritor y el viajero se encuentran en el cruce de caminos de la memoria con la imaginación, en cuanto ámbito de mostración del recuerdo "presentificado" y de lo posible "soñado" (Aventura 82). De hecho, el escritor-viajero vive en esa tensión estética derivada de una indagación personal acerca de lo evocable y de lo escribible. En contraposición al "sedentarismo paradójico" del flâneur hipermoderno, el escritor barcelonés prefiere "urbanizar" los zapatos gastados que pintara Vincent van Gogh. Por ello, más que convertirse en observador relativamente inmóvil de la movilidad, Argullol practica un pensamiento peripatético: la crónica de un éxodo existencial, literario y estético convertido en proyecto transformador de un modo de vida. Como asevera Luis Arturo Guichard: "como única forma de reconciliación consigo mismo y con su tiempo, el

8 Para Becanovic, en cambio, más que esa "deconstrucción de la autobiografía", Visión desde el fondo del mar supondría una suerte de autoficción compuesta a partir de un tejido de diferentes géneros literarios: "une concordance discordante littéraire originale" (152) que recoge la experiencia nómada -temporal y espacial-, fragmentaria y plural del sujeto y del mundo. 
Argullol novelista, el poeta y el ensayista optan por un viaje que conduce al equilibrio, siempre provisional y precario, del conocimiento" (“Aventura").

Por añadidura, si se sigue la idea del viaje como encuentro con la otredad, independientemente de la estrategia empleada, este implica un tránsito entre espacios más o menos delimitados. Para María Rubio, el libro de viajes formaliza la deriva textual del yo sobre un territorio cultural y geográfico, "pero también la resistencia del yo y hasta un nuevo protagonismo del yo" (67-68). En su ensayo clasificatorio, la profesora Rubio habla del "libro de travesía" en el que desaparece o se difumina el itinerario geográfico del yo hasta el punto de que la única movilidad es la de la propia subjetividad:

La memoria personal empieza a ganar terreno hasta imponerse como el único trayecto posible. Se inicia el viaje al centro del yo (...). El viaje, entonces, se convierte en travesía. Travesía en un tiempo que fluye libre, sin barreras, y en un espacio que es el de todos los instantes que conforman nuestra cartografía íntima y secreta, nuestro mito personal. (86-88)

En este caso, el flâneurismo se centra en el movimiento ambivalente de un saber "a la aventura", un conocimiento que sobrepasa los tradicionales polos "yo" o "mundo" como modos excluyentes de aprehensión. La transversalidad funge de pasarela que, a la vez que interconecta e integra tanto los ámbitos como los focalizadores cognoscitivos, "nos hace participar de una unidad superior y nos sugiere que hemos penetrado en el corazón del enigma" (Argullol, El cazador de instantes 21-22). Eso sí, para Argullol existe un peligro continuo, en realidad, nada extraño a cualquier proceso mental: la búsqueda de "centros" conceptuales, puntos de apoyo o asideros que permitan fijar las ráfagas de una razón.

De todas formas, el nomadismo absoluto resulta una entelequia, como se demuestra por la existencia de mecanismos de territorialización innatos como la memoria, que habilita la construcción de un "relato" o, al menos, la narrativización de ese encadenamiento de impresiones. De acuerdo con Rubio, es evidente que el lenguaje proporciona una arquitectura lógica para los fragmentos, además de permitir la visibilización de "huellas de presencias y de ausencias" que van a hilvanar una red de imágenes sobre las páginas (86-87). De esta suerte, la transversalidad argulloliana elabora un entramado de intensidades "aforísticas" en las que el yo se sitúa siempre al borde de una escritura fuertemente temporalizada. Por eso, el nómada, el viajero, en vez de trazar círculos concéntricos en torno al punto imaginario que se desea 
desentrañar, vive, en cambio, en la provisionalidad. A semejanza de Heráclito, y pese a que el autor reconoce la "necesidad" de algún tipo de ancla, Rafael Argullol nunca navega dos veces en el mismo río. Como el autor explica en el fragmento 318 de El puente de fuego:

Nuestro gran error ha sido obligarnos continuamente a buscar un centro: un Dios, una Razón, un Rey, un Imperio, un Universo. Hemos abatido el vuelo de nuestra imaginación con los disparos mortíferos de una Realidad escandalosamente mutilada, y cuando la tentación de la libertad ha sido demasiado grande hemos encallado en la roca de nuestros miedos para, desde allí, proclamar que habíamos varado la nave en el punto justo. Necesitamos creer que siempre hay un centro. Pero el auténtico navegante sabe que nunca arroja el ancla en el mismo lugar (El ancla). (121)

Ciertamente, la obra de Argullol demuestra una profunda autoconciencia, pues la escritura transversal bordea siempre el abismo de su finitud, aunque, al final, ejerce un movimiento de apertura que la salva de su fijación. La transversalidad subraya la actividad dinámica del pensamiento que tiene su fin y su medio en sí mismo y en las reverberaciones ahí evocadas. En términos del creador:

La escritura debe dejar constancia de nuestra deriva, aunque asimismo de nuestro afán por orientarnos en el mar de errores como si la búsqueda de una verdad fuera posible. Es, simultáneamente, testimonio de la pérdida de uno mismo y ficción de su rescate. Visión del naufragio desde la ilusión de la supervivencia (Deriva y rescate). (El cazador de instantes 44-45)

No obstante, se debería evitar cualquier asociación que sugiriera una "vía unitiva" que, de forma casi redentora, salvara a la escritura de la entropía de los fragmentos. La escritura transversal no se libra de los condicionamientos inherentes a su soporte y a las particularidades de las formas breves y, especialmente, de la literatura sapiencial. Es más, sin entrar a valorar la macroestructura que los sujeta al orden estricto de las páginas, cada libro guarda una curiosa relación con la totalidad. Si se aplica la acertada metáfora del cirujano y del cartógrafo (Argullol, Aventura 347-348) a su obra, se confirma la presencia de, al menos, un doble punto de vista sobre el conjunto. Por un lado, el "cirujano" es "meticuloso, incisivo y despiadado" en su disección de la realidad; es decir, este modelo de escritor prefiere extirpar un 
pedazo de mundo y colocarlo bajo un potente microscopio para resaltar un aspecto concreto. Por otro, el "cartógrafo" se emplaza en el ángulo cenital, lo suficientemente alejado para obtener una visión panorámica del territorio.

En efecto, la escritura vive entre estos dos extremos que, respectivamente, singularizan o universalizan la experiencia de lo observado ${ }^{9}$. Con todo, la transversalidad muestra de manera inmediata las carencias de cada perspectiva -la microperspectiva aísla el fenómeno de su tejido relacional mientras que la macroperspectiva lo invisibiliza por la complejidad y el exceso de conexiones-; de ahí que Argullol no proponga en su escritura ninguna síntesis, sino la copresencia de cada plano en ambas dinámicas:

(...) En esta doble metáfora de la cartografía y de la cirugía se hace evidente, desde luego, que la escritura se despliega siempre en el interior de una tensión provocada, de un lado, por el ánimo de introspección $\mathrm{y}$, de otro, por la exigencia de universalidad. Pero la doble metáfora actúa también en la dirección opuesta: en los mapas se lee el espíritu de las ciudades y países del mismo modo en que las heridas nos adentran en el alfabeto secreto de los hombres. (Aventura 348)

Aun cuando los textos transversales presentan, en ocasiones, un tono simbólico, críptico u oracular, próximo a la aforística moderna y contemporánea, la poética de Rafael Argullol no se solaza en la superficie de un lenguaje pretenciosamente abstruso o inaccesible. Como diría Benjamin: "Subrayando, patética o fanáticamente, el aspecto enigmático de lo enigmático no hay avance posible; el misterio lo penetramos sólo en la medida en que lo reencontramos en lo cotidiano" (Obras 313-14). En el autor, la paradoja de

9 De hecho, así la define Rafael Argullol en su Breviario de la aurora: "Escritura: Cirugía y cartografía con palabras" (40). Esta dualidad también ha sido personificada mediante las figuras paradigmáticas de Parménides y Heráclito. En una interesante conversación con la especialista Tamara Djermanovic, el escritor catalán explica que ambos filósofos representan "las dos caras del ser". En palabras de Argullol: "por un lado, el ser se manifiesta en su inmutabilidad, en su unidad y en su eternidad y, por otro, se expresa en su diversidad y contingencia (...). En cierto modo, algo de esto he aplicado en mi metodología literaria, pues hurgo en las capas internas de la realidad a través de un microscopio de la palabra. Cuando llego a una excesiva intimidad giro la lente y convierto el microscopio en telescopio y busco lo más universal. Y cuando llego a lo universal que roza lo abstracto, giro la lente de nuevo, y voy a lo particular. La existencia es tanto aquello que nos proporciona el telescopio como el microscopio; aquello que nos proporciona la visión inmutable de Parménides, como aquello cambiante que nosotros anclamos en Heráclito" ("Visiones desde la tradición..." 228). 
la transparencia estriba en la habilidad para expresar con claridad y sencillez pensamientos complejos ${ }^{10}$. Antonio Porchia formuló en una de sus célebres voces -"Lo hondo, visto con hondura, es superficie" (61)-que existe un tipo de profundidad en la superficie que no se fundamenta en la hermenéutica tradicional, sino que, en cierto modo, conculca el célebre axioma con el que Wittgenstein cierra el Tractatus lógico-philosophicus: "De lo que no se puede hablar hay que callar" (132). Por su parte, la escritura transversal del barcelonés se alimenta del "excedente" de sentido no expresado ni, quizá, expresable, excepto por la mística:

Los que se expresan oscuramente para resaltar la profundidad de sus pensamientos recuerdan a estas alimañas de los pantanos que no pueden soportar la luz. No hay ideas oscuras sino deseos imposibles. Pero incluso éstos se pueden expresar con toda claridad (Los pantanosos). (Argullol, El puente de fuego 50)

Paradójicamente, cada "instante" cazado o recolectado con sumo cuidado sale al encuentro de la impresión causada en el observador, de tal manera que ese "flechazo" no solo apunta a la realidad, sino que también se dirige de vuelta hacia el arquero. De esta manera, la escritura transversal hiere y es herida por la experiencia de una temporalidad que siempre regresa al momento presente ya sea en forma de eco o resonancia en el sujeto. Además, la obra inclasificable de Rafael Argullol sobrepasa los límites materiales de la hoja impresa, pues su poética se abre a la multiplicidad y al non finito como promesa futura y testimonio presente de un pensamiento inacabado y nómada. Por esta razón, el acabamiento, aun cuando concita la figura de la perfectibilidad, supone una amenaza castradora para la libertad que se le presupone a la razón sensible argulloliana, crítica con cualquier declaración que suscite un retorno al (antropo)centrismo cosmológico, existencial o tecnológico.

A la luz de todo lo señalado, se podría afirmar sin excesivos matices que la única ley natural ante la que responderían estas formas es la de la excepcionalidad: cada palabra "primigenia", cada aforismo "revelador" constituye un espacio tensivo y de mostración. La escritura de Rafael Argullol se sitúa en la intersección entre identidad y otredad, entre el yo y el no-yo,

10 Sobre este punto, resulta muy sintomático que Rafael Argullol siempre titula los fragmentos. 
entre lógos y enigma, entre "la multiplicidad de la experiencia y la aspiración al ser o a la unicidad" ("Escritura transversal" 37). Principalmente, su creación opera de un modo copulativo según su primera acepción del Diccionario de la Lengua Española -"que ata, liga y junta una cosa con otra"-y según su sentido biológico, ya que, en cierta forma, las palabras van a copular unas con otras para generar sentidos no previstos en la literalidad del lenguaje. Tal como se ha venido señalando a lo largo del apartado, la apuesta por el nomadismo expresivo trasciende su cualidad espacial y deviene una verdadera estética de lo inestético o de lo paraestético. A fin de cuentas, el nómada se define, según el ensayista barcelonés, en los siguientes términos: "Oteador de horizontes, rastreador de huellas" (Breviario 84).

\section{CODA AFORÍSTICA}

Se ha convertido en un lugar común señalar el parentesco entre el género aforístico y la escritura transversal de Rafael Argullol. Ahora bien, el barcelonés, como ya manifestaran Gómez de la Serna, Porchia o Derrida, no se siente identificado con el poder acotador de la palabra aforismo. Aunque reconoce el "aire de familia" con las formas breves -aforismos, pensées o máximas(El puente de fuego 11-12), estima que la reducción terminológica supone, de algún modo, limitar la energía y la proyección de las composiciones: "Los disecadores de ideas nunca podrán ofrecer una copa de vida. En los laboratorios del pensamiento se trabaja con luz artificial. Y, hoy como ayer, a las cepas les hace falta el sol" (El cazador de instantes 35).

Por ejemplo, los 360 fragmentos de El cazador de instantes articulan una diégesis del pensamiento por iluminaciones, una narrativa relativamente sujeta a vectores de integración. Pese al carácter provisorio e inmediato que suele atribuirse a las estructuras diarísticas y, en general, a las escrituras del yo, Argullol va a disponer en su obra "pequeñas cristalizaciones de una literatura nómada" (El puente de fuego 12). En este sentido, cada texto presenta, por un lado, esa cualidad fragmentaria -no subordinada e independiente- $y$, por otro, exhibe su completitud y fuerza relacional "inter-aforística". De hecho, él mismo aclara que "el espacio genuino del Cuaderno de travesía es el de los intersticios: una escritura en la frontera y asimismo una escritura sobre la marcha" (El puente de fuego 12).

Giorgio Agamben se pregunta si sería posible elaborar un "discurso que, sin ser un metalenguaje ni hundirse en lo indecible, diga el lenguaje mismo y 
exponga sus límites" (36). En mi opinión, este interrogante se ha extendido al ámbito de las formas artístico-literarias, concebidas como plasmaciones de una verdad oculta que aguarda su revelación en esa suerte de llamada lingüística a la presencia. Es más, existen ciertas expresiones que, justamente por su cualidad "deforme" o "informe", se han vinculado con modos discursivos esenciales o metaformas, a partir de las cuales se "actualizarían", en términos de Jolles (1971), todas las demás. El aforismo y, con mayor éxito, el fragmento se han impuesto, sobre todo, desde el siglo XIX como el tipo de escritura más próxima a las propias dinámicas del pensamiento. De alguna manera, la fragmentariedad ha formado un tándem metafórico con la visión paratáctica y espontánea de la creatividad actual.

Igualmente, cabe cuestionarse si la transversalidad actuaría desde los mismos parámetros que el fragmento -forma ya consagrada por la tradición literaria. Los géneros literarios son entidades “temporalizadas" y, por tanto, poseedoras de un cierto desarrollo evolutivo que los va resemantizando en función de las variadas interpretaciones históricas. Como menciona Argullol en su "Prólogo" al libro de aforismos de Ricardo Martínez Conde Cuentas del tiempo:

Naturalmente, el aforismo es un tipo de expresión que se adecua a la transversalidad literaria. Es, al mismo tiempo, poesía y pensamiento, narración e idea. El escritor de aforismos va dejando señales en su camino, insinuando el rumbo pero velando la meta. Sus verdades son provisionales porque sabiamente renuncia a apropiarse de la verdad. ("Prólogo" 16)

En principio, si nos atenemos al aspecto "externo", los Cuadernos de Argullol están compuestos por un conjunto de textos que presentan los rasgos prototípicos del género aforístico. Si bien la condición lapidaria del aforismo se mantiene, el "ayuno de palabras" (El cazador de instantes 72) conlleva una diferencia cualitativa respecto a la mera economía verbal ${ }^{11}$; así, lo breve se vuelve denso e, incluso, esencial, pues en un entorno menos saturado de signos, los "supervivientes" allí inscritos gozarán de mayor visibilidad y 
relevancia ${ }^{12}$. La concisión se corresponde con la conocida metáfora del iceberg que aplicara Ernest Hemingway para la narrativa; sin embargo, en Argullol la imagen de esa gran masa de hielo no solo incide en la idea de que bajo la superficie se oculta la mayor parte de la información, sino que también encerraría una peligrosa belleza por descubrir. Por ello, la contemplación de la totalidad requiere bucear en sus secretos, adentrarse en un abismo de significados que remeda la "ascesis" por inmersión:

47. Siempre hablamos sólo de la punta del iceberg. Cuando nos aproximamos a la roca blanca nos deslumbra la luz cegadora y aunque admiramos su belleza nos alejamos de ella alertados del peligro. No obstante si, excitados por su contemplación, nos atrevemos a dejar la superficie para sumergirnos en las profundidades seguiremos viendo tan sólo la punta del iceberg pues, pese a que ahora se ha agrandado la montaña de hielo que tenemos delante, y también su belleza y su peligro, lo que vemos sigue siendo su cima. Únicamente en muy pocos casos llegaremos al fondo, y la contemplación será total, pero entonces ya no regresaremos a la superficie y, si lo hacemos, no poseeremos palabras para contarlo (El iceberg). (Argullol, El puente de fuego 33-34)

Adicionalmente, aparte de las dimensiones reducidas y sin caer en esa citada y paradójica anticorrelación correlativa forma/contenido de lo fragmentario, derivada de su apertura transgenérica, la escritura transversal se va a debatir entre la visión filosófica y la visión trágica representadas por dos escenarios fundacionales de la existencia y de la literatura (Argullol, El cazador de instantes 48-49): el viaje-movimiento exterior y el viaje-movimiento interior, cuyos epígonos "clásicos" se encontrarían, respectivamente, en la épica de la Odisea y en la tragedia de La peste. De acuerdo con esta perspectiva, Rafael Argullol estima que el "filósofo" exhibe una única pasión: la búsqueda de la Verdad y del Bien como ideales de perfección; en cambio, frente a esos grandes constructos filosóficos, el "héroe trágico" se sitúa en una posición indeterminada en el polarizado espectro del régimen heroico, ya que este indaga en esa sabiduría de la duda y de la imperfección "desde el interior de las pasiones humanas" (El cazador de instantes 20). No obstante, gracias a la transversalidad, el escritor puede congeniar-sin reconciliación- un querer ser

12 Como sentencia Argullol: "Un día de silencio, de tanto en tanto, fortalecería el valor de las palabras" (El cazador de instantes 72). 
y un querer saber que se sitúa con vehemencia en el intervalo ético-estético para contrarrestar cualquier devaneo metafísico o moralista del pensamiento:

224. No sabemos lo que sabemos pero sí intuimos lo que queremos saber, no sabemos lo que somos pero sí intuimos lo que queremos ser. Entre ambas intuiciones, entre el querer saber y el querer ser, transcurre el cauce de la filosofía. A veces exige la lectura de un texto abstruso; a veces, jugar. En ocasiones nos requiere para la conversión o para el amor; en otras, simplemente, para que nos detengamos al margen del camino y, en silencio, escuchemos la música del viento. (Intuiciones). (El puente de fuego 91)

Por otro lado, en Breviario de la aurora, Argullol somete las entradas de su Enciclopedia del crepúsculo a una operación "estética" de aquilatamiento expresivo bajo unos criterios más o menos establecidos para componer un corpus de trescientas sesenta definiciones dispuestas en orden alfabético: "ninguna de ellas podía superar las tres líneas, siendo preferible, en las más, un laconismo todavía mayor" (Breviario 7). La Enciclopedia constituye una verdadera "enciclopedia personal" en la que el ensayista compila una serie de reflexiones "de actualidad" publicadas durante veinticinco años en prensa y otros medios. Esta obra, calificable como "complementaria" de un libro "mayor" 13 , está concebida a partir de un criterio cuantitativo -la extensión-, pese a que presenta también un matiz desambiguador: la catalogación de los textos como acepciones o definiciones aforísticas de un número de voces léxicas que conforman el repertorio conceptual que despliega el autor en toda su producción. Por ejemplo, obsérvense las siguientes "palabras clave" del pensamiento argulloliano:

Arte: La máscara y lo que queda cuando cae la máscara. (14) $* * *$

Bosque: Nuestra retirada para preparar nuestro retorno. (19)

Contemplación: La acción en detenimiento. (26) ***

Exilio: Nuestra patria anterior y nuestra patria futura. (42) ***

13 Sin ir más lejos, la relación entre los términos crepúsculo-aurora resulta muy elocuente. 


\section{Literatura: Experiencia + experimento. (73) $* * *$}

Recuerdos: Cuando tiramos la piedra es difícil saber la profundidad del pozo. $(103)^{14}$ $* * *$

Saber: Saber vivir está por encima de cualquier saber. (109)

Asimismo, pese a que la escritura transversal parece adscribirse a las vertientes lírico-aforística y ensayística de la brevedad, se aprecian otras plasmaciones que juegan con las fronteras narrativas como esta especie de microrrelato con toques fabulísticos:

161. Miró a los ojos del hombre que iba a ejecutarle. El tiempo se detuvo en el instante inmenso de aquel duelo de miradas. Cuando sonó el disparo mantuvo los párpados abiertos hasta el último aliento. $\mathrm{Y}$ al fin cayó mortalmente herido, eterno vencedor de su verdugo (El condenado). (El puente de fuego 69)

Si tal como expresa el autor, la "Acrobacia" se puede definir en los siguientes términos: "saltar al vacío y alcanzar el cielo" (Breviario 11); de un modo similar, la literatura transversal propone un salto sin red al lector del que solo la inteligencia y la sensibilidad pueden salvarlo de la aparatosa caída. La escritura aforística ha recurrido habitualmente a la comparación con el funambulista, el acróbata o el prestidigitador para destacar el delicado y sutil equilibrio conceptual y retórico que ha de mantener el género. En este sentido, comenta el autor que "las ideas deben tener sombra" (El puente de fuego 46-47) si no quieren ser consideradas un juego lingüístico insustancial o un mero artificio destinado a perecer en aguas poco profundas.

En suma, el arte transversal de Rafael Argullol estriba en la capacidad de sorprender la realidad desde los múltiples ángulos de un pensamiento y de un lenguaje extraños a cualquier enfoque o cauce genérico exclusivos. La aforística y la escritura transversal se instalan en el espacio común de lo

14 Como muestra de la "complementariedad" o relación intertextual, compárese esta definición con su contexto original en Enciclopedia del crepúsculo. Concretamente, el texto se inserta en una reflexión más extensa titulada "La Edad de Oro": "Aquella noticia perteneció desde el principio a la Edad de Oro. ¿O fue, quizá, el inicio de ésta? No puedo jurarlo, pero aseguraría que fue el primer acontecimiento del que tengo memoria. Con respecto a los recuerdos, cuando tiramos la piedra es difícil saber la profundidad del pozo" (13-14). 
transgenérico, aunque tal vez se debería precisar que dicho hábitat resulta tan atractivo como peligroso por su inestabilidad para cualquier orden estético impostado, pretendido o preestablecido. Aun así, además de fundar un territorio de posibilidades creativas, cualquier límite o tabú produce un efecto inesperado: alimenta el estímulo para traspasar sus lindes y aventurarse en los espacios intermedios y en las "infinitas periferias" (Argullol, Aventura 28) que, de manera involuntaria, instituye cualquier prohibición. Como manifiesta con clarividencia el autor en un texto fechado en 1987:

Para enfrentarse a este mundo ya no sirve la solución integradora ni tampoco la recurrencia a una drástica especialización expresiva. La volubilidad y enmascaramiento de una realidad descompuesta exigen, a su vez, una escritura voluble, rica en máscaras, que obliga a una continua transmigración entre regiones aparentemente separadas (...). No dan lugar a la formación de nuevos géneros, sino simplemente a modos híbridos en los que se refleja la necesidad de desbordar la reducida y fragmentaria visión a la que obliga el mundo con respecto al que se ha perdido toda ilusión de unidad. No obstante, es precisamente esta obligada fragmentariedad, y la consecuente insatisfacción que despierta, la que empuja al escritor hacia zonas fronterizas de la expresión. (Aventura 576-577)

\section{BIBLIOGRAFÍA}

Agamben, Giorgio. La potencia del pensamiento. Anagrama, 2008.

Alonso Cano, Oriol. Experiencia de la ausencia. Incapacidad cientifica para abordar lo prerreflexivo. Anthropos, 2015.

Argullol, Rafael "Provincianos y cosmopolitas." El País, 1 ene. 2016, http://elpais.com/ elpais/2015/12/18/opinion/1450431738_159745.html Aventura. Una filosofía nómada. Acantilado, 2008.

El cazador de instantes. Cuaderno de travesía 1990-1995. Acantilado, 2007. Breviario de la aurora. Acantilado, 2006.

Enciclopedia del crepúsculo. Acantilado, 2005.

El puente de fuego. Cuaderno de travesía 1996-2002. Destino, 2004.

“El velo de Isis.” El País, 20 feb. 2000, http://elpais.com/diario/2000/02/20/ catalunya/951012442_850215.html.

"Escritura transversal: literatura y pensamiento." Boletín Informativo de la Fundación Juan March, № 253 (1995): 33-38. 
“Prólogo". En R. Martínez Conde, Cuentas del tiempo. Pre-Textos, 1994. Territorio del nómada. Destino, 1993.

Argullol, Rafael y Tamara Djermanovic. "La filosofía, arte del pensar." Razón y fe, t. 273, $\mathrm{N}^{\circ} 1408,2016$, pp. 107-119.

"Visiones desde la tradición estética y filosófica para el mundo global-Diálogo entre Rafael Argullol y Tamara Djermanovic-." Universitas Philosophica, № 62 (2014): 223-238.

Bachelard, Gaston. La intuición del instante. FCE, 1999.

Becanovic Nikolic, Zorica. "L'identité narrative dans Visión desde el fondo del mar de Argullol". Penser l'autofiction: perspectives comparatistes, coordinado por Adrijana Marcetic, Isabelle Grell y Dunja Dusanic, Université de Belgrade-Agence universitaire de la francophonie, 2014, pp. 145-153.

Benjamin, Walter. Obras. Libro II. Volumen 1. Abada, 2007.

Libro de los pasajes. Akal, 2005.

Buci-Glucksmann, Christine. Estética de lo efímero. Arena libros, 2007.

Bundgaard, Ana. Más allá de la filosofía. Sobre el pensamiento filosófico-místico de María Zambrano. Trotta, 2000.

Cappannini, Cecilia Beatriz. "La constelación benjaminiana como efecto de montaje." Arte e Investigación, $\mathrm{N}^{\circ} 9$ (2013): 45-49.

Galán, Julio César. "Horizontes sobre el ensayo de Rafael Argullol.” Cuadernos Hispanoamericanos, $\mathrm{N}^{\circ} 785$ (2015): 104-12.

Guichard, Luis Arturo. “Aventura. Una filosofía nómada, de Rafael Argullol.” Letras Libres, 31 oct. 2000, http://www.letraslibres.com/mexico/libros/aventura-una-filosofia-nomadarafael-argullol.

Heidegger, Martin. Arte y poesía. FCE, 2010.

Infante del Rosal, Fernando. "Argullol o el pensamiento sensible." Laocoonte. Revista de Estética y Teoría de las Artes, vol. 1, No 1 (2014): 156-61, https://ojs.uv.es/index.php/ LAOCOONTE/article/view/4391.

Jolles, André. Las formas simples. Editorial Universitaria, 1971.

Juarroz, Roberto. Poesía vertical. Cátedra, 2012.

Maffesoli, Michel. El instante eterno: el retorno de lo trágico en las sociedades posmodernas. Paidós, 2005.

Elogio de la razón sensible. Una visión intuitiva del mundo contemporáneo. Paidós, 1997.

Porchia, Antonio. Voces reunidas. Pre-textos, 2006.

Rubio Martín, María. "En los límites del libro de viajes: seducción, canonicidad y transgresión de un género." Revista de Literatura, vol. LXXIII, № 145 (2011): 65-90.

Sánchez Ferlosio, Rafael. Campo de retamas. Pecios reunidos. Random House, 2015.

Schlegel, Friedrich. Fragmentos seguido de Sobre la incompresibilidad. Marbot, 2009.

Steiner, George. Nostalgia del Absoluto. Siruela, 2001.

Valente, José Ángel. Obras Completas II. Ensayos. Galaxia Gutenberg, 2008. 
Wittgenstein, Ludwig. Tractatus lógico-philosophicus. Alianza, 2010.

Zambrano, María. El hombre y lo divino. FCE de España, 2007. 